\title{
Relação das pessoas e instituições que doaram obras ou revistas á Biblioteca da Faculdade no periodo com- preendido entre 15 de maio e 15 de agosto de 1934
}

\author{
Abelardo Marinho \\ Académie de Droit International de la Haye \\ Adelaide Castro Alves Guimarães \\ Affonso José de Carvalho \\ Almachio Diniz \\ Anais da Assernbléa Legislativa Provincial de S. Paulo \\ Antonio Piccarolo \\ Antonio Pinto Cardozo de Mello \\ Arquivo Nacional de Caracas \\ Associação Brasileira Pró - B. I. T. \\ Associação dos Funcionarios Publicos do Estado de S. Paulo \\ Biblioteca Nacional \\ Biblioteca Nacional de Buenos Aires \\ Biblioteca Publica de Jaboticabal \\ Biblioteca Rio-Grandense \\ Boletim de Ariel \\ Carl Duisberg \\ Carnegie Endowment For International Peace \\ Centro Agricola "Luiz de Queiroz" \\ Centro Espirita Cristão \\ Chefatura da Policia de S. Paulo \\ Cia. Editora Nacional \\ Clovis Bevilaqua \\ Clovis Ribeiro \\ Cooperativa dos Empregados da Viação Ferrea do Rio Gran. \\ de do Sul \\ Decio Ferraz Alvim \\ Departamento Estadual do Trabalho \\ Departamento Nacional do Café \\ Deparatmento Nacional de Estatistica \\ Diretoria Geral do Ensino do Estado de São Paulo
}




\author{
Djalma Forjaz \\ E. M. Carvalho Borges \\ Embaixada do Mexico \\ Empreza Editora "O Pensamento" \\ Ennio Monteiro Galembeck \\ Ernesto Leme \\ Escola Politecnica de S. Pauso \\ Escola de Sociologia e Politica de São Paulo \\ Estado de S. Paulo" ("O) \\ Faculdade de Direito e Ciencias Sociais de Buenos Aires \\ Faculdade de Direito de Recife \\ Faculdade de Medicina de S. Paulo \\ Fernando Gallage \\ Francisco C. Bendicente \\ Francisco Ribeiro dos Santos \\ Giorgio Del Vecchio \\ Giustizia Penale (La) \\ Guia Fiscal - Dr. Spencer Vampré \\ Imprensa Oficial do Estado \\ Industrias y Finanzas - Buenos Aires \\ Industrias Reunidas F. Matarazzo \\ Instituto de Café de S. Paulo \\ Instituto de Engenharia de São Paulo \\ Instituto Historico e Geografico Brasileiro \\ Instituto de Organização Racional do Trabalho. S. Paulo \\ Irmandade da Santa Casa de Misericordia de São Paulo \\ J. F. de Mello Nogueira \\ J. F. Moreno \\ J. M. de Azevedo Marques \\ J. M. Vilhena Barbosa de Magalhães \\ João Baptista Martins de Menezes \\ João Edmundo Caldeira Brandt \\ João da Gama Cerqueira \\ João Pimenta \\ João Rodrigues de Mereje \\ Jorge Americano \\ José Carlos de Macedo Soares \\ José Joaquim de Almeida \\ Julio Revoredo \\ Legação do Equador \\ Leonel Vaz de Barros \\ Livraria Jacyntho \\ M. F. Pinto Pereira \\ Manoel Viotti
}




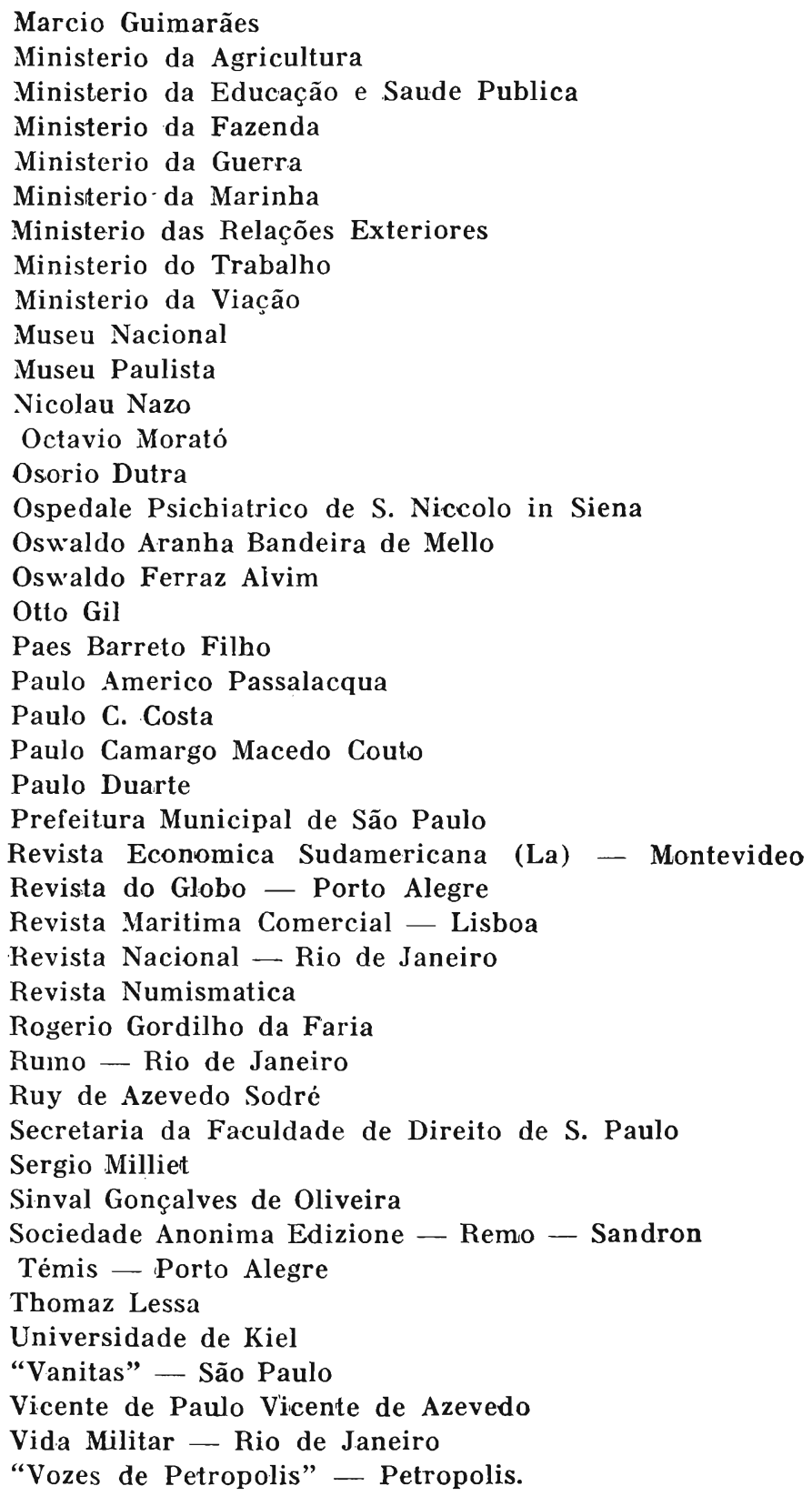

